\title{
Children's perceptions of scientists, and of themselves as scientists
}

\author{
Martina Dickson ${ }^{1}$, Melissa McMinn², Dean Cairns ${ }^{1}$ and Sharon Osei-Tutu ${ }^{3}$ \\ ${ }^{1}$ Emirates College for Advanced Education, Abu Dhabi, United Arab Emirates \\ ${ }^{2}$ Higher Colleges of Technology, Abu Dhabi, United Arab Emirates \\ ${ }^{3}$ Independent Education Consultant, United Kingdom
}

In rapidly developing countries such as the United Arab Emirates (UAE), where this study took place, having a body of competent, dedicated key workers in STEM fields is critical to growing national economies. This, in turn, requires motivated, wellqualified graduates of STEM degrees. School students' perceptions of science, scientists and science careers have been shown in some research to affect uptake of science degrees later on. How much of their science classwork students experience as authentically 'feeling like scientists' is less understood, yet important. This study took place in upper primary science classrooms in the UAE. Immediately following a science lesson, children were interviewed in focus groups ( $n=66$, with an approximately even gender split). Broad questions were explored, such as whether they felt like 'real scientists' when they 'performed' science in the classroom, whether they enjoyed science, and their science career aspirations. 83\% of students stated enjoying science, while $61 \%$ would like to have a career involving science in the future. The interview data revealed that, overall, children mostly disagreed that their classroom science was reflective of work a 'real scientist' would do, chiefly due to perceptions of a lack of discovery element in their work, which suggested to them a lack of authentic science exploration, and of the work not being dangerous enough. Students frequently reported feeling that they were 'following steps' because the teacher 'already knew the answers', which was different from the work of a scientist. The implications of these findings to classroom practice are discussed.
ARTICLE DETAILS

LUMAT General Issue

Vol 9 No 1 (2021), 643-669

Received 26 May 2021

Accepted 31 August 2021

Published 21 September 2021

Pages: 27

References: 46

Correspondence:

martina_dickson@hotmail.com

https://doi.org/10.31129/

LUMAT.9.1.1605

Keywords: Children, science classroom, scientists, perceptions

\section{Introduction}

In rapidly developing nations such as the United Arab Emirates (UAE), having a highly skilled and qualified STEM workforce is paramount to lofty national ambitions of a strong Knowledge Economy by 2030 and of "science and technology [forming] the pillars of a knowledge-based, highly productive and competitive economy"1. Having this kind of currency in workforce is dependent upon universities graduating highly motivated, competent science and technology graduates. This, in turn, is heavily dependent upon students having opted for those degrees in the first place. An

1 https://www.vision2021.ae/en/uae-vision/list/united-in-knowledge 
examination of students' perceptions of science is therefore prudent in Gulf countries such as the UAE, but also internationally, as countries strive to meet the growing needs of $21^{\text {st }}$ century society.

Trujillo and Tanner (2014) explain the importance of taking an "inventory of our students' science identities" (p.13) in order to encourage students towards careers in science. This study explores the ways in which students' science identity - their perceptions of themselves as scientists - in the classroom compare with their thoughts about the work which 'real' scientists perform and their thoughts on science career aspirations. We also wished to explore their enjoyment of science and identify particular areas of enjoyment, or reasons for lack of enjoyment, to provide a context within which to explore their 'possible self' science identities. It is thought that by focusing on primary age children, it may still be early enough to influence perspectives on classroom science and these 'possible selves' with reference to 'real' scientists, in order to positively impact science career perceptions and outcomes.

\section{Literature Review}

It is often reported that students' positive experiences in the science classroom affect multiple outcomes, including positive science identification, science aspirations and later uptake of science in higher education (Archer et al., 2010; Aschbacher et al., 2010; Bennett \& Hogarth, 2009). It is also true that negative science classroom experiences can, conversely, dampen science career aspirations and pursuit of science in higher education (Archer et al., 2020; Lyons, 2006). The way in which children experience science in their classrooms is complex and a factor of multiple variables.

\subsection{Students' Perceptions of themselves 'Doing Science'}

Research into how primary school students think of themselves as 'doing science' in school has generated a diversity of findings, such as being involved in hands-on investigations, completing their workbooks, learning from their teacher, working alone and doing 'dangerous' things (Zhai et al., 2014). The students in the Zhai et al. (2014) study also reported themselves 'acting like a scientist' when they were doing experiments. Students' understanding of authentic science experiences was explored by Hsu and Roth (2010) in the form of documentation of high school students' experiences of science internship. 'Authentic' was explained as denoting "forms of engagement that have a considerable degree of family resemblance with what 
individuals in science-related fields really do and experience" (p. 292). However, Archer et al. (2010) found that students who reported engaging in informal science activities outside of school, such as experiments with household chemicals in their kitchens, were not necessarily extending this engagement to their classroom science. Instead, they often posited these experiences as being 'naughty'. Boys were seen to be particularly prone to using these descriptions to perform hegemonic masculinity, while girls often reported more formal interactions with science outside of class, such as reading science texts. These interactions did not necessarily lead to stronger engagement with classroom science.

Schinske et al. (2016), whilst researching science identity and stereotype threat, chose to focus on the concept of 'possible selves' over 'role models', arguing that the concept of these 'possible selves' could be more useful than a more typical role modelling concept. They and we, as a team of researchers, felt that the students would be more likely to identify with themselves as scientists if they saw their own possible selves reflected. Referring to Schinske et al.'s work, this meant in practice that we chose to focus on how students thought of themselves as scientists, rather than exploring their perceptions of others as scientist role models. To enable this, it was critical to explore students' ideas of how their own work and activity in science class compared with what they thought scientists did, rather than limiting the study to their perceptions of scientists' work only. This is a subtle yet important difference, and this comparative 'possible self' reflection is hopefully a more effective means of examining the likelihood of students being inclined towards science careers.

\subsection{Student's Science Identity and Self-Efficacy}

Science identity and self-efficacy are both seen to positively impact 'using and doing' science (Williams \& George-Jackson, 2014). Many studies have shown disparity between genders in science self-efficacy and identity (e.g. Archer \& DeWitt, 2015; Banchefsky et al., 2016), suggesting that classroom practices are critical to both genders. This is perhaps even more poignant for nations where one gender underperforms in school-level attainment, as in the case of boys in the UAE (Schleicher, 2018). Positive science identity and career aspirations have also been found to be developed by science research experiences, mentoring and community involvement (Aschbacher et al., 2010; Chemers et al., 2011). One's perception of self as being good at school science and one's sense of having an identity as a scientist are of course not necessarily conflated. Some students do perceive themselves as being 'good' at science 
yet would not necessarily consider themselves to be classroom scientists. To encourage students' commitment to science careers, researchers must look carefully at how students' science identities play out within the science classroom setting itself (DeWitt et al., 2013). Children's science identity impacts upon how they place themselves within the classroom arena. Students with strong science identity, for example, may exhibit greater confidence in taking initiative with unfamiliar or challenging science activities, including practical activities (Kim, 2018). By contrast, students who do not identify themselves as being able to do science, being 'good' at science, or 'doing' science in the classroom at all, are not considered to have strong science identity. This may manifest itself in a number of ways, such as hesitancy or a lack of participation in the class (Carlone et al., 2014).

\subsection{Students' comparisons of their work with that of 'real' scientists}

"Am I Like a Scientist? I feel like a scientist when I do dangerous things"

Student response (Zhai et al., 2014)

Students are more likely to embody being a scientist when they believe what they are doing in class closely resembles what a 'real' scientist does. The way in which science is 'done' in the classroom, therefore, may strongly impact students' views and attitudes towards science, making a distinction between classroom science and 'real' science. Jaber and Hammer (2016) argue that there is much to be learned from the emotions and feelings experienced by students within science, for example the excitement and engagement in learning that a student feels when they experience a new idea. A science teacher's positioning may also act to nurture students' identity in science by encouraging perseverance and providing opportunities for students to become excited about science (Kim, 2018). Various research about stereotypes of science and science learning, such as science being filled with hard and dry content, laboratory experiments and male-dominated work environments, have resulted in feelings of distance from science in students' minds. This affects inclinations towards following careers in science and their likelihood of enjoying school science (Archer et al., 2020; Aschbacher et al., 2010; Bøe et al., 2011). The premise of this logic is that if students enjoy lessons more, they may be more likely to be drawn towards science subjects and possibly science careers later. This enjoyment may be developed by a variety of means such as particular forms of learning; inquiry based, problem-based, 
project-based learning, more of a hands-on approach, and integrating technology with learning (Jaber \& Hammer, 2016). For example, a multi-level path analysis using data from 54 countries included in the PISA 2015 cycle demonstrated that inquirybased science instruction was associated with significant improvement in students' enjoyment of science. Additionally, analysis of this data for students in the UAE (Cairns \& Dickson,2021), Taiwan and Australia (Wang et al., 2021), showed that students who enjoyed science were significantly more likely to aspire to enter a STEM career than students reporting lower levels of enjoyment.

\subsection{Study Purpose}

The purpose of this study was to explore aspects of the science classroom experience in which children are likely to 'feel' like scientists. Vice versa, if they did not feel like scientists, we wished to explore why, and whether this was a factor of having a strong identification with, and enjoyment of, science in the first place. We also explore the students' perceptions of what 'real' scientists do.

The underlying justification for carrying out this work is that in countries such as the UAE, there are shortages in national citizens within their STEM workforce (which is currently mostly outsourced to expatriates), and yet the National Vision and indeed plans for future economy are built upon the predication that this will change in the near future. However, in order to have cohorts of students who select STEM subjects in higher education (and take up STEM careers following this), students need to have the interest, self-efficacy, and identifiably positive perceptions of the work which scientists do in the first place. This study therefore seeks to identify preconceptions which students hold, which could potentially affect this uptake, but which could be over-turned too. The study has novelty in that we are not aware of any qualitative work in the Middle East and Near Asia (MENA) region specifically looking at students' comparative perceptions of the classroom work they do with the work of scientists. Internationally, much science attitudinal or dispositional research is undertaken using quantitative fixed response data. Qualitative data, particularly group interviewbased, is known to be a relative rarity even internationally, aside from a few highprofile studies, such as the longitudinal ASPIRE project led by Louise Archer, and to which we refer in this article. 


\subsection{Research Questions}

The study aimed to answer the following research questions:

Q1. What areas of enjoyment of science do students report?

Q2. How do primary students perceive themselves to be 'doing' science in the classroom?

Q3. What perceptions do students have of the work of scientists, and how does this compare with their own science classroom experiences explored in Q2?

Q4. What science career aspirations do students report?

\section{Methodology}

In this section, we describe the methodology used in this qualitative study. We first describe the participants, the recruitment methods used, the methods for carrying out the focus group interviews, the way in which the interview data was analysed, and finally the ethical considerations of the study.

\subsection{Participant Recruitment}

The participants were selected via stratified, convenience sampling in terms of the site choice, due primarily to researcher familiarity with administrators in local schools who had expressed keen interest in participation in research studies. Both public and private schooling options are available in the UAE, with public schools following the UAE's Ministry of Education curriculum, and private schools following a variety of international curricula. All schools are supervised and monitored by local regulatory bodies. For this study, three different private school sites were involved, all coeducational, and each following a different international curriculum (American, British, Canadian). The 66 participants were all in Grade 5 or 6, aged approximately 10-11 years old. The gender split of the sample group was approximately 50\%, with 34 girls and 32 boys. Due to the confidential nature of the participation in the research, we were not aware of the nationalities of the students, but each school had a proportion of national (Emirati) students within its student body, which ranged between 30\% and 90\%. In each school, all children in Grade 5 or 6 were invited to participate in the study in order to give a reasonable reflection of attitudes within those grade levels. 
Although all three schools were co-educational in theory, one of the three schools was segregated by gender from grade 6 onwards, and so some single-gender classes were included in the study. Grade 5 students were taught science by their homeroom teacher, who also taught other core subjects, and science lessons took place within the general classroom. Where students were Grade 6 , they were taught by a science specialist teacher and utilized a dedicated science lab for lessons. At the time of the study, students were learning about topics related to chemistry and earth sciences.

The interviews took place immediately following a science lesson. These were focus group interviews consisting of between three and five children, so a total of fifteen interviews. Each interview lasted between 20-30 minutes. This allocation of time was discussed within the research team, and was aimed for as a compromise of a suitable duration for children of this age, and being able to gather reasonably indepth data. By having only five questions, this ensured that the children were not conceptually over-loaded during the interview duration. These were planned in cooperation with the school administration and class-teachers so that the interviews would take place at a time most convenient and least disruptive. For some schools, this meant selecting a lesson from the schedule, which backed onto a break, or for others this meant that the interviews took place during the second lesson of a double science lesson. One interview took place per group, in a quiet area close to the science classroom. The interviews were audio-recorded and later transcribed.

We chose to adopt the focus group approach, as opposed to one-on-one interviews, in part due to the known propensity of this method when working with vulnerable populations, such as students, to help participants feel more at ease. We hoped that they would therefore be more likely to speak authentically, and so provide valid and reliable data, albeit with a requirement of careful and skillful interviewer guidance (Lewis, 1992). It also allowed for a combination of interviewing techniques to be utilized, such as use of 'group interview' techniques when individual standpoints or opinions were sought (e.g. do you enjoy science? Why/why not?), and also for 'group discussions' whereby the researcher's prompts lead students to discuss questions (Savin-Baden \& Major, 2013). By interviewing the children in their normal school and classroom setting, we reasoned that thoughts of science would be fresh in their minds. In this way, we attempted to create a setting for naturalistic enquiry in as far as possible, in other words: "obtaining data in as natural a setting as possible" so as to "minimize influence of an unrealistic research environment" (Newby, 2010, p. 117). We utilized in-depth interviewing techniques, exploring the 'why' question frequently, 
and adopted a semi-structured approach based upon the interview guide framework. See appendix for interview schedule. This allowed for flexibility to allow participants to elaborate upon issues they considered to be important where appropriate.

The study was reviewed and approved by our IRB, and we also received approval from the educational authority council in Abu Dhabi to approach the schools in order to recruit participants to the study. Both student assent and parental consent were sought for their participation in the study. Verbally, we used child-friendly language to explain to students at the beginning of the interview that they could refrain from answering any question they wished to, and that they could withdraw at any time. We also explained that their names or schools would not be identifiable from any published work in relation to the study.

\subsection{Data Analysis}

The data transcripts were first read repeatedly by each member of the research team. The analysis of the interview data was predominantly based upon thematic analysis whereby themes and sub-themes were defined, where particular themes clustered in alignment to research questions (Robson, 2011). Initially, preliminary coding and the process of categorizing common codes took place (Johnson \& Christensen, 2014) which were then carefully analysed for repetition and saturation, so that themes emerged such as 'more exciting', 'more dangerous' and 'philanthropic'. Within each of these themes, sub-themes were also developed. We were aware of the criticisms surrounding the use of ICR (intercoder reliability), such as that it is sometimes seen as an "unwarranted attempt to import standards derived for positivist research" (O'Connor \& Joffe, 2020, p. 4). However, we also believed that a system of coding where we would be accountable to one another as team members was more likely to lead to consistency, subscribing to the view that this self-awareness of our own coding would incentivize to code to a high standard (O'Connor \& Joffe, 2020).

We adopted the strategy often used by researchers whereby the principal investigator carried out the initial segmentation based on conceptual breaks, and generation of relevant codes (Campbell et al., 2013). These were then shared with the team, followed by a group discussion of overlaps and divergences (Thomas \& Harden, 2008) and adjusted on the basis of these discussions and initial analyses. We also worked with a coding frame which included possible examples of text which would align with this code, and also exclusions to that particular code (Roberts et al., 2019). This helped to reduce the coding variation between the team members. Our ICR 
calculation, using Cohen's kappa coefficient, was 0.81. This is deemed by various researchers to be a figure indicative of acceptable and sometimes substantial levels of agreements (Burla et al., 2008; Lombard et al., 2002).

By using narrative analysis, we explored the individuals' spoken statements of their accounts of what they have experienced in the science classroom, and their personal voice describing where their possible selves as scientists in the classroom sit with their perceptions of the work scientists do. In narrative analysis, this individual voice reflects a combination of students' attitudes, concerns and priorities (Newby, 2010) and provides insight into their perspectives. Additionally, codes pertaining to science enjoyment and science classroom experiences as per the research questions, were extracted and categorized. By following this process systematically, we were satisfied that the codes were saturated to these classifications. This process of coding and iterative sub-coding was undergone with each subsequent interview analysis until it appeared that new theories ceased to emerge, but served to support previously established themes (Bryman, 2012). An example of this would be in relation to students' ideas about differences between the science which they did in the class, compared to the science which they perceived scientists to be. We also exercised reflexivity through critical and continual self-reflection about our predispositions, biases and the potential impact of these elements in our interpretation of research findings and conclusions (Johnson \& Christensen, 2014).

\section{Findings}

In alignment with our research questions, the findings are reported here in relation to students' enjoyment of science, the perceived work of scientists, and the differences between classroom science and the work of scientists. Finally, the science career aspirations of students are reported.

\subsection{Students' Science Enjoyment}

We asked the students to state whether or not they enjoyed science, and if so, what specifically they liked about it, or conversely, if not, what they disliked. The vast majority of children $(55 / 66,83 \%)$ stated that they enjoyed science. Most of their explanations for this enjoyment connected to ideas about the opportunities which science provided to carry out experiments, in particular those with unexpected results or visual drama. Responses related to this include: 
P1: I like doing experiments that amaze me!

P5: That's the best thing. To make an explosion!

P23: Explosions, bombs! Cause I like mixing them.

In the same vein, science was described by some students as being particularly appealing where there were elements of danger. One student described a favourite lesson where they had created 'elephant toothpaste':

P19: It's dangerous ... it's like this stuff that's really, really hot, and it can burn your skin off

Likewise, science activities and experiments which dramatically repulsed were often cited as favourites, such as:

P42: I like the bread experiment ... we were trying to figure out how mould grows on bread... It was disgusting!

Perceived fun and entertainment aspects of science seemed to feature frequently in responses, as these examples illustrate:

P13: I like it cause it's entertaining.

P27: Experiments are fun.

P51: You might have some fun with learning science and other chemicals and other things.

Students frequently referred to the appeal of novelty in science experimenting, including the appeal of things that they could not do in other subjects. This was particularly the case when a variety of science experiments were offered to them. This added to the appeal, since students appeared to relish not knowing what to expect:

P63: I like doing experiments - things that I didn't do before.

P18: Science is interesting, it's fun. I think that like there's always something new to find.

P1: I like it because you get to experience more things that you haven't known in your life. 
One student referred to enjoying achieving results which were new to themselves and to others, as this comment shows:

P57: My favourite thing is like, when you do your experiments and you get your results, but everyone gets different results.

Several comments referred to the mixing of chemicals as particularly 'fun'. There were also references to other branches of science, such as biology or astronomy:

P32: Like, if we learn about digestive and nerve system, I loved it.

P44: I like to see bones. Microscopes and bones.

P 12: I like animals and I like studying about animals, that's a strong factor.

P 35: I love science a lot, because the first time when I've been taught, I learned about the planets and space, and I want to be an astronaut when I grow up. And when I knew that Hazza2 is the first astronaut in Emirates, I was so happy for him.

There were references to liking science, in particular, when compared with other subjects, namely mathematics, where students felt they did not have opportunities for hands-on learning:

P17: I like science since I think you get to do a lot of different things. Cause in math, I just feel like it's torture and all you do is just sit, and add, and add, and add.

P35: We get to experiment with stuff, unlike maths.

P2: I love when we do experiments. I don't love when we do math.

Students who stated that that they did not like or enjoy science $(11 / 66,17 \%)$ tended to do so for three main reasons; either that they considered it 'boring', or that it was perceived to be a difficult subject which was somehow out of their reach. They also stated not enjoying science because even when they did do experiments, these were considered to be too safe to be exciting, as one student emphatically stated:

\footnotetext{
${ }^{2}$ Emirati astronaut, Hazza Al Mansouri, made a voyage to the International Space Station as the UAE's first astronaut during the weeks these interviews took place.
} 
P65: I want it to be dangerous!

Those that considered science to be boring, shared the following:

P13: I don't like it when we do reviews. Yeah, it's good for us, but we already know it, why do we study it again?

P39: We watch videos and we write, and then another video and then we write. We take a lot of notes.

A small number of students described their lack of science enjoyment as being chiefly due to their perceptions of science being 'hard' and almost unobtainable, as these two students explain:

P27: I just think, like, science is really hard, and I, like, never get it. Like, what's a pure substance? Even if I study a lot, I'll still not get the best mark.

P59: I'd say no, because sometimes ... I don't get it, there's a lot of stuff to remember, like how, okay - so there's oil and water and you have to remember where does the oil go where does the water go, how do you separate them, all those stuff. And for science you have to like know the degrees and all those stuff are really hard.

\subsection{Students' Perceptions of Scientists' Work}

Students were asked to describe the kinds of work which they believed scientists do, which fell into three main categories. Firstly, that scientists tend to perform work which leads to discovery, trying and failing, or by venturing to unfamiliar and unknown places, as these statements show:

P42: Try to discover new things, no-one ever knew about.

P12: Undiscovered places that no-one has been to.

Interestingly, whilst students had referred to themselves liking science when working with chemistry experiments such as mixing and exploding things, scientists were frequently referred to in these direct responses as working within a diverse range of fields such as geological, meteorological, and pale ontology types of work. For example,

P48: Like, they discover, like, minerals. Like, why natural disasters happen, and why chemical reactions happen. 
P11: They research, like, why the weather changes, different weathers.

P6o: I think scientists discover things, like new animals, minerals, and also do experiments with bugs. And they also do experiments, like animals, do experiments with plants, different types of things.

P21: They find bones, like bones from us, and animal bones, they find these.

Scientists' doing good' and contributing positively to global issues was also a theme in the students' responses, from researching cures for illnesses such as cancer, to testing for food safety, for example:

P27: I think scientists conduct experiments, that people have been trying to find, like to solve it, to solve like cancer.

Some students spoke negatively of the work which some scientists are involved in, such as animal testing for spurious purposes, and explained their feelings of towards this ab/use of science:

P63: And they make experiments on frogs or about them.

P13: Using creams, they start with animals and then they - if it's good, they put it out for people to use. Many animals die because of the experiments. It's not good.

Some students also talked about ideas of scientists doing 'difficult work' and solving problems, as the following statement demonstrates:

P18: I think scientists do work that includes a lot of things that humans cannot acquire with special equipment, cannot acquire with just a certain brain - not anybody can be a scientist, you have to be qualified. You have to go through hours of learning and memorizing to actually become a scientist.

Statements such as this one strongly implied a sense of intellectual 'elitism', in who was capable of becoming a scientist.

\subsection{Students' Perceptions of themselves as Scientists}

Students were asked to discuss whether there was a difference between the work which scientists did, and their own work in the classroom, thereby prompting a reflection of scientist as 'possible self', as referred to earlier. Responses were mixed, though more tended to think that the work was not the same, for example: 
P23: Yes [there is a difference], because the one that we do is basically not a real scientific work ... because we didn't know as much as the scientist workers, they took a long period of years to learn about it, and worked on it, so we can do less than what they can.

An over-riding theme in the responses, to explain why their classwork was not like 'real' scientists, was that scientists chiefly performed work which was much more intellectually or conceptually challenging than their own on a much larger, more complicated scale. On comparative reflection, this led many students to explain the science they do in the classroom as being childish, less important, and less 'difficult', as these statements show:

P33: You kind of do all the small things, that a scientist does in the classroom, but when you're a scientist you do harder things, very much harder.

P13: Most scientists are adults. So they are more responsible and they get to do more ... stuff. They get to do more complicated experiments.

P14: Yeah we do childish stuff and they do more bigger and better things.

And they have like different chemicals words, like not child-friendly ones.

Key to the differences between what the students perceived as their own and scientists' work were the students' perceptions of a lack of discovery element in their classroom work. Students frequently referred to the fact that their classroom work generally involved pre-determined steps, ones which it was obvious their teacher had previously set out, removing the 'unknown' element of their work. Some examples of representative statements are:

P5: Yes, when scientists work they don't know the answer, they are trying to discover something. But in the classroom the teacher already gave you the plan to learn. So you have to find that out but you already know the steps from the teacher.

P32: I think that scientists are more advanced in their experiments than us doing things in schools. When they're doing the experiments and working, they're going freely, not following ... if someone tells you - we're going to be working on this, you have to follow this and you have to do that

Students also frequently referred to scientists as performing much more 'dangerous' work than them, which pertained to them, therefore, being less like a scientist: 
P24: Of course we're not going to use chemicals or something. The most dangerous thing we did in science was the teacher using a lighter. I think when you're a scientist you use more dangerous chemicals, and more effective stuff to humans.

P56: They do, let's say, dangerous stuff, but we do safe stuff, so we don't get hurt. [Why do you think we don't do anything dangerous at school?] Cause we're still young. If we got hurt it would be the school's responsibility cause if we do something hurt, or dangerous ... the school might shut down.

P19: Real scientists would risk their life for doing things in real science. They do things which are ... more dangerous than we do.

These descriptions of danger were frequently set against their own experience of 'safe' science, such as:

P51: They have like safety gadgets, but we don't. We don't need it, we're already safe cause we're doing safe projects.

P48: Because we're just little kids and not sensible.

P5: They (scientists) use goggles and safety things.

Another key theme in students' perceptions of differences in work was that scientists were also more likely to require complex materials and equipment to perform their work, but this was also where students thought there were similarities between their classwork and a scientist's work:

P28: And [as a scientist] you get to, you have to use all the equipment ... they use these ... machines that can find, for example, the temperature and these things.

P37: Like, you guys use equipment and stuff, we don't... us, we don't, we just learn and we do projects and we take papers.

P50: I think we don't do the same thing in school, because scientists use more professional things to separate substances, and we use like not very good things to separate substances, because we have like plastic items and like not really stable items, but you guys have like more stable items and better glasses than us.

\subsection{Students' Science Career Aspirations}

Finally, we asked students about their own career aspirations with regards to being a scientist and whether it was a career they would have considered. Of the 66 students interviewed, $61 \%$ stated that they would like to either be a scientist or have a career 
which used science in some ways. Of those students who answered categorically no, that they did not want to work in science or as a scientist, responses are categorized according to themes such as everything already having been discovered (e.g. I think they discovered everything in life!). Others explained their reticence, regardless of whether they enjoyed science, they worried that (again) they did not have the intellectual capacity, or worried somehow about how 'hard' the subject would be:

P38: I feel like I would never be qualified to be a scientist because I have a really bad memory. Like a terrible memory.

P50: No. You have to be really good at it.

Those who answered 'yes' explained this either as wanting to again discover new things or places, or cure illnesses, much like the earlier descriptions of scientists' work. Some also expressly wanted to become scientists due to the perceived propensity of the work to provide opportunities to carry out 'dangerous experiments'. Some students also felt inspired by the possibility of making discoveries of new things, not for discovery itself, but more for the fame that this discovery would bring, e.g. "if I invent something new, new for the planets then maybe I'm gonna be famous!". Many of those who stated 'yes', then elaborated that they were interested in careers which used science, such as engineering or medicine, while others stated that while they liked science and enjoyed science class, they simply had passions in other areas such as teaching: "I love science, but I don't want to be a scientist. I don't know why, I just love many other things". Two mentioned that they would like to be the type of scientist "who works with animals".

\section{Discussion}

Overall, the findings were positive, with more students than not enjoying their science lessons and some reporting an interest in pursuing a career that involves science. However, qualifying statements by the students suggest that these positive findings are true only when certain criteria are met. We now discuss this, and consider the implications for classroom practice.

\subsection{Science Enjoyment}

As reported in the previous section, many students referred to chemistry experiments as being synonymous with enjoyable science. There were references to a greater 
diversity of science work beyond chemistry, such as enjoying lessons in biology, anatomy ('bones') and astronomy. That $83 \%$ of the students reported enjoying science is a positive finding, though it was often dependent upon the particular science lesson. It could be perceived as problematic that students particularly warmed to dangerous science examples, since it indicates limited views of what science is, and what scientists do, and in turn of children's sense that they can indeed become scientists. The other aspect of enjoyment was in the concept of novelty and examples of science which were unfamiliar both to themselves and to others. The expectation (or experience) of science as a subject with opportunities for hands on learning meant that it sometimes 'trumped' other subjects deemed to be less interactive. The handson element of science lessons has been found to be a common reason that students enjoy the subject (Archer et al., 2010; Osborne \& Collins, 2001). There was a strong sense of expectation that science, as a supposedly exciting and active subject, perhaps should not involve such mundane activities as writing and note-taking.

\subsection{Scientists' Work}

That the children often described the work of scientists as revolving around discovery is not new, and this idea prevails across literature even as far back as the 1960s. This is not necessarily inaccurate. Whether it is the chief, omnipresent work of scientists is debatable though, and poses the question as to why students would not be experiencing a sense of discovery in their own science classrooms. This is explained in students' responses as being due to the fact that teachers not only already know the answers to set problems, explaining why students feel that there is a lack of discovery element in the work. A further key reasoning for why classroom science is not the same was the fact that scientists' work was considered to be dangerous. Many students thought that inside the classroom, teachers had a responsibility to protect children from dangers, so they could not perform 'unsafe' work (again, not untrue). This did however, result in children feeling that what they performed in the classroom did not leave them 'feeling like scientists'.

Some interesting, and positive, perceptions of scientists' work which arose included finding solutions for global problems such as natural disasters and diseases, but also negative work such as testing medicines and cosmetics on animals. Just as their enjoyment depictions related to more diverse science topics than the previously found predicted chemistry related experiences (e.g. Chambers, 1982; Kane, 2016) so too did the descriptions of scientists' work surpass this. A diversity of science work 
was referred to such as geology, ecology, and animal- and weather-related work. Finally, the idea that science is something difficult and challenging, and outside of the reach of many, was referred to quite often, and was consistent with previous studies (see for example, Archer et al., 2010; Archer et al., 2013). This was positioned within narratives explaining why they themselves did not feel like scientists, for example the student who described science as being something one "cannot acquire with just a certain brain". Where comparisons were drawn and seen between classroom science and 'real' science, as some students termed it, they tended to be in relation to processes such as the scientific method ("we learn, they learn, they hypothesise, we hypothesise). A final distinction was in the associations with equipment, which many felt scientists used ('gadgets'!) and children in schools did not.

\subsection{Science Career Aspirations}

Analysis of the 2015 UAE PISA data showed that a one-point increase in enjoyment of science was related to a $19 \%$ increase in the probability that a student would aspire to enter a STEM career (Cairns \& Dickson, 2021). However, our study did not particularly reflect this, since fewer students were interested in a career either as a scientist, or in which science was involved (61\%), than had stated they enjoyed science (83\%). In other words, articulation of enjoyment of science in the class did not necessarily indicate a desire or aspiration towards a science career. Reasons for this included perceptions of other career choices as being more appealing, and ideas of science being only for the 'brilliant'. Various work has shown that girls are more susceptible to stereotypes associating genius with science (the 'mad, brilliant scientist!'), which discourages and dissuades many from entering STEM degree programs (Bian et al., 2017; Leslie et al., 2015). Although we do not focus specifically in this paper on gender comparisons, we note that both boys and girls were equally likely to make these kinds of comments in our study. Three-quarters of the students who reported enjoying science did express an interest in science-related careers. The reasons for this interest included being able to indulge in danger, and again the opportunity to discover, and perhaps become famous too along the way. 


\section{Implications for Classroom Practice}

Criticisms of the gap between school science and 'real' science are not new, and calls continue to be made to increase the "real-world" relevance of science to better engage young people (e.g. Archer et al., 2010). The concept of danger appeared, as with many other studies, to be the all-important appeal of science in the current study. It could be worthwhile for science teachers to emphasize elements within science curricula where there are opportunities for visual drama or danger, and which require some level of protection in a strongly monitored and structured environment. However, as mentioned earlier, this favouring of 'dangerous' science does indicate a narrow conception of science. We suggest that science classrooms can instead be framed expansively as spaces that engage students in the ways of talking and reasoning of scientists, such as in the raising of questions, the noticing of inconsistencies, the sense-making about everyday phenomena, presenting those practices as central to the work of science and to sense-making, therefore broadening this view of science as 'danger'.

Pragmatically, many primary schools do not have access to labs or equipment, and because of this perhaps, science may become infantilized or reduced in form. Whilst we fully appreciate that good science education can take place without the need for labs or indeed expensive equipment, we are anecdotally aware that this often results in teachers performing rather superficial experiments, or simply avoidance of implementing science curriculum where this is not tightly governed in schools. This avoidance might of course be connected to teachers' own science self-efficacy, and may explain some of the disconnect in perceptions between classroom science and 'scientists' science'. We suggest that, if it is possible to sometimes expose children, particularly in upper primary levels, to lab environments and where possible to bring elements of those labs (such as boxes of equipment) into the classroom setting, this is more likely to result in students feeling indeed like 'real scientists'. This may also help teachers; in a study correlating the beliefs and practices of Abu Dhabi's private school teachers of science, over $90 \%$ of all participants self-reported beliefs in line with current best practice (for example; group work, learning through inquiry, and time for reflection on learning), but also reported that they do not have enough physical space that enables them to teach science (47\%), nor have enough materials and resources (42\%) (Kadbey et al., 2015).

The idea of scientists being discoverers can definitely, we feel, be addressed in primary science classrooms. Since it appears that the clear following of steps somehow 
spelled out for students how predictable their work was, and how therefore 'not' like a scientist it was, teachers can work to develop the element of suspense in lessons, perhaps providing students with more opportunities to plan, and develop learning opportunities such as paths of inquiry learning, and being given flexibility with the way they choose to carry out some investigations such as what they are investigating (choices of topics, or equipment), choice of variables to investigate and control, and so on. Less prescriptive, inquiry focused learning activities that are similar to the work of scientists (used as a context for reflection) have been shown to improve conceptions of the nature of science, conceptions that, in turn, are reported to strengthen students' science identities (Lederman \& Lederman, 2014). For example, a study involving year 5 and 6 students in Australian schools participating in an inquiry focused science community of practice, revealed that students' perceptions of science and the work of real scientists were transformed by this approach (Forbes \& Skamp, 2019). Students' prior views about science (teacher-directed with limited opportunities for exploration) changed during the ten week project such that they described their current science lessons as collaborative, creative, challenging, and perhaps most importantly as an effective way of understanding "how the world works" (Forbes \& Skamp, 2019, p. 480). The possibility of discovering a range of solutions to scientific problems and gathering data through a range of methods also responds to the point students made the present study regarding the appeal of good science lessons that involve features of inquiry as being in novelty; or as they put it, "feeling that your results were different from anyone else's". These inquiry elements of their science classrooms; doing experiments, finding different results, using equipment, are where the students in this study reported feeling most like scientists. As such, these are the activities in which students are most likely to develop positive science identities and see their possible selves reflected, and therefore should be emphasized within the classroom. In other words, primary science lessons should be designed in such a way to "offer students avenues to see themselves as people who can do science and see science as a way to engage with the world so they might find their own place in it and make their own contributions" (Kane, 2016, p.115). A further implication of this is relevant to teacher education in the UAE, since this would be important to reflect upon, review existing courses and professional development for pre- and in-service teachers and include this in the curriculum.

Indeed, science identities have been shown to be positively impacted in primary science classrooms where students are referred to as scientists, are encouraged to act 
like scientists who raise questions and seek answers through research, and in which collaboration, making mistakes, and accidental findings are expected (Kim, 2018). Beyond the primary classroom environment, authentic, inquiry focused science experiences were offered to marginalised grade 10-12 students in an urban high school in the south-eastern US. Students carried out research-related activities for a local biofuels research group and overall developed more diverse perceptions of science and scientists and improved recognition of themselves as scientists (Chapman et al., 2017).

However, when developing students' views on science inquiry in order to encourage the development of their science identities, it should be noted that students (Concannon et al., 2020) and teachers (Cigdemoglu \& Köseoğlu, 2019) often have naïve views regarding the purpose of science inquiry processes. Although we would recommend students participate in inquiry-based learning experiences, simply doing inquiry in the classroom is not sufficient to develop an understanding about inquiry. For example, students may be very good at controlling variables in an experiment but may have little understanding as to why they are doing so. Studies that employ the Views About Scientific Inquiry (VASI) questionnaire indicate that naïve views relating to scientific inquiry can be further improved by explicit-reflective instruction about scientific inquiry (Lederman et al., 2014).

A positive shift in science identities is likely to, at least in part, address the references to science as being hard, challenging, and by implication, out of reach for many. The perception that science is a particularly challenging subject echoes the findings of Archer et al. (2010). They reported that the sentiment of the challenge was appealing to some, causing primary school children to "imagine[d] that the science they would encounter in secondary school would be even harder and that this would be "a good thing" because it would require them to "use our brains more" (p.13). We did not see evidence in our study of this sense of difficulty as inspiring children to rise to the challenge. This implication, that science was accessible to a select few is prohibitive to students making choices, not only long-term in science subjects and degrees, but also in every day participatory choices in the science classroom. Archer et al. (2010) also noted that the perceived necessity of being 'brainy', 'geeky', and 'smart' was perceived by some students as attractive, and perhaps in itself providing appeal: "the hard or difficult nature of science was something that many of the students reported as attractive." (p. 12). Again, we did not see evidence of this potentially positive side to perceptions of difficulty in our study. Therefore, 
opportunities for small successes in science, to boost self-efficacy, may serve as a starting point. Furthermore, some research has shown effective use of life story documentation, focusing on the life stories of key scientists, and emphasizing elements such as some who had not enjoyed, or were not perceived to be 'good' at science at school, but also those who had struggled with ideas or recognition for many years, had some success at over-turning students' views on the need for brilliance in science (Schinske et al., 2016). Whilst this study was carried out in a community college, involving teenage students, this approach can be emulated with ageappropriate resources at primary and secondary science level too. A focus on a 'cool', but familiar, relatable local personality, such as UAE astronaut Hazza Al Mansouri, may work well in the current context. Learning collaborations in science communities of practice involving practicing scientists and engineers visiting and mentoring primary school children, in the previously mentioned study by Forbes and Skamp (2019), resulted in children expressing a sense of pride, excitement and an increased sense of "awareness" regarding the work of scientists. Such approaches allow for the development of more realistic perceptions of science and scientists and should considerably strengthen science identity in primary aged children.

The research by Kim (2018) indicating the way in which science teachers' positioning can help to develop students' identity, excitement and perseverance, is also important in this context. Since the students in our study refer to a lack of discovery and danger as key reasons for not identifying classroom science with 'real science', teachers can deeply reflect and examine the way in which they position work which should genuinely have elements of inquiry and discovery. For example, the teacher in the Kim (2018) study positioned herself as a scientist, modelling curiosity, excitement, confusion, perseverance; but also as a teacher, learner, researcher, and problem solver alongside her students, to positive effect. The teachers variously positioned the students into these roles as well.

Lastly, to complement the implementation of more authentic science learning experiences, primary science teachers could also develop students' capacity for developing their own experiments, within frameworks of student-led risk assessments. If students are to choose equipment and methods for investigating science phenomena, they need to become competent in identifying, assessing and mitigating risks in the science classroom thus allowing for the safe use of a wider range of substances and equipment. As students develop this capacity the range of experiments they can design and safely execute will increase, thus reducing the gap 
between school science activities and the practices of working scientists. If we are to provide authentic experiences in terms of discovery and inquiry for children in the science classroom, then we must also provide them with "training" that simulates the health and safety considerations that scientists regularly employ in the workplace.

\section{Conclusion}

Our study shows that even where students enjoy science, there is still considerable resistance to them identifying their 'possible selves' with scientists. We see this clearly in the way that many students do not identify the work they perform as 'real science', which appears to be remote from the work of the 'real scientist' for many. This study adds to the growing evidence that attitudes towards scientists, and by extrapolation students' science career aspirations, are often steeped in perceptions of elements of genius and brilliance being required. Similarly, to other research in different international regions, the work of a scientist is categorized as chiefly discovery and danger based, leading many students not to see what they do in the science classroom as being 'like a scientist' at all. This favouring of 'dangerous' science does indicate a limited notion of science. However, since these attitudes are likely to impact on their 'possible self' identity as scientists, we consider that we have a responsibility as science educators to provide opportunities for a broader view of 'danger' that incorporates questioning, sense-making, and discovery of the unknown as a vehicle to engage students in science. Unfortunately, the use of danger can also reinforce stereotypes, and this need be handled with care. However, the excitement which danger generates in students could also be inspired through more discovery and exploratory types of science inquiry.

One positive feature of our study findings is that much enjoyment of science lessons is experienced, yet this too is conditional upon particular characteristics. We believe that schools can adopt a two-pronged approach to addressing these issues. One of these is to provide children with more advanced, realistic conceptions of science and scientists by increasing the exposure that students have to 'real' scientists; divulging not only the diversity and relative safety of their work but also the ways in which it is conducted, highlighting collaboration and work in contexts beyond the stereotype of a lone scientist working in a chemistry lab. The second approach we recommend is for teachers to consider adapting science learning experiences to include the elements that would allow students to 'feel more like a scientist'. These might be, for example, the inclusion of specialist equipment even in the general 
classroom setting, satisfying the proclaimed need for 'gadgets', and to closely review ways in which planned lessons can incorporate elements of inquiry learning which are perceived to be missing, for example by allowing students to make more choices, plan more independently, be assigned different tasks, and not simply 'already know the steps from the teacher'. Further research should increase the diversity of schools included in order to include a greater number of UAE national student participants.

\section{Acknowledgements}

The authors would like to thank the school teachers and administrators for their support and time in facilitating this study, and would especially like to thank the student participants for their time and responses.

\section{References}

Archer, L., \& DeWitt, J. (2015). Science aspirations and gender identity: Lessons from the ASPIRES project. In Understanding student participation and choice in science and technology education (pp. 89-102). Springer, Dordrecht. https://doi.org/10.1007/978-94007-7793-4_6

Archer, L., DeWitt, J., Osborne, J., Dillon, J., Willis, B., \& Wong, B. (2013). 'Not girly, not sexy, not glamorous': Primary school girls' and parents' constructions of science aspirations. Pedagogy, Culture \& Society, 21(1), 171-194.

https://doi.org/10.1080/14681366.2012.748676

Archer, L., DeWitt, J., Osborne, J., Dillon, J., Willis, B., \& Wong, B. (2010). “Doing” science versus "being" a scientist: Examining 10/11-year-old schoolchildren's constructions of science through the lens of identity. Science Education, 94(4), 617-639.

https://doi.org/10.1002/sce.20399

Archer, L., Moote, J., Macleod, E., Francis, B., \& DeWitt, J. (2020). ASPIRES 2: Young people's science and career aspirations, age 10-19. https://discovery.ucl.ac.uk/id/eprint/10092041/

Aschbacher, P. R., Li, E., \& Roth, E. J. (2010). Is science me? High school students' identities, participation and aspirations in science, engineering, and medicine. Journal of Research in Science Teaching, 47(5), 564-582. https://doi.org/10.1002/tea.20353

Cairns, D., \& Dickson, M. (2021). Exploring the Relations of Gender, Science Dispositions and Science Achievement on STEM Career Aspirations for Adolescents in Public Schools in the UAE. The Asia-Pacific Education Researcher, 30(2), 153-165. https://doi.org/10.1007/s40299-020-00522-0

Kadbey, H., Dickson, M., \& McMinn, M. (2015). Primary teachers' perceived challenges in teaching science in Abu Dhabi public schools. Procedia-Social and Behavioral Sciences, 186, 749-757.

Banchefsky, S., Westfall, J., Park, B., \& Judd, C. M. (2016). But you don't look like a scientist! Women scientists with feminine appearance are deemed less likely to be scientists. Sex Roles, 75(3-4), 95-109. https://doi.org/10.1007/s11199-016-0586-1

Bennett, J., \& Hogarth, S. (2009). Would you want to talk to a scientist at a party? High school students' attitudes to school science and to science. International Journal of Science Education, 31(14), 1975-1998. https://doi.org/10.1080/09500690802425581 
Bian, L., Leslie, S. J., \& Cimpian, A. (2017). Gender stereotypes about intellectual ability emerge early and influence children's interests. Science, 355(6323), 389-391.

https://doi.org/10.1126/science.aah6524

Bøe, M. V., Henriksen, E. K., Lyons, T., \& Schreiner, C. (2011). Participation in science and technology: young people's achievement-related choices in late-modern societies. Studies in Science Education, 47(1), 37-72. https://doi.org/10.1080/03057267.2011.549621

Bryman, A. (2012). Social research methods (4 $4^{\text {th }}$ Ed.). New York: Oxford University Press.

Burla, L., Knierim, B., \& Barth, J. (2008) From text to codings: Intercoder Reliability assessment in qualitative content analysis. Nursing Research, 57(2), 113-117.

https://doi.org/10.1097/01.NNR.0000313482.33917.7d

Campbell, J. L., Quincy, C., Osserman, J., \& Pedersen, O. K. (2013). Coding in-depth semistructured interviews: Problems of unitization and intercoder reliability and agreement. Sociological Methods \& Research, 42, 294-320. https://doi.org/10.1177/0049124113500475

Carlone, H. B., Scott, C. M., \& Lowder, C. (2014). Becoming (less) scientific: A longitudinal study of students' identity work from elementary to middle school science. Journal of Research in Science Teaching, 51(7), 836-869. https://doi.org/10.1002/tea.21150

Chambers, D. W. (1983). Stereotypic images of the scientist: The Draw-a-Scientist Test. Science education, 67(2), 255-265. https://doi.org/10.1002/sce.3730670213

Chapman, A., \& Feldman, A. (2017). Cultivation of science identity through authentic science in an urban high school classroom. Cultural Studies of Science Education, 12(2), 469-491. https://doi.org/10.1007/s11422-015-9723-3

Chemers, M. M., Zurbriggen, E. L., Syed, M., Goza, B. K., \& Bearman, S. (2011). The role of efficacy and identity in science career commitment among underrepresented minority students. Journal of Social Issues, 67(3), 469-491. https://doi.org/10.1111/j.15404560.2011.01710.X

Cigdemoglu, C., \& Köseoğlu, F. (2019). Improving Science Teachers’ Views about Scientific Inquiry: Reflections from a Professional Development Program Aiming to Advance Science Centre-School Curricula Integration. Science \& Education, 28(3-5), 439-469. https://doi.org/10.1007/s11191-019-00054-0

Concannon, J. P., Brown, P. L., Lederman, N. G., \& Lederman, J. S. (2020). Investigating the development of secondary students' views about scientific inquiry. International Journal of Science Education, 42(6), 906-933. https://doi.org/10.1080/09500693.2020.1742399

DeWitt, J., Osborne, J., Archer, L., Dillon, J., Willis, B., \& Wong, B. (2013). Young children's aspirations in science: The unequivocal, the uncertain and the unthinkable. International Journal of Science Education, 35(6), 1037-1063.

https://doi.org/10.1080/09500693.2011.608197

Forbes, A., \& Skamp, K. (2019). 'You actually feel like you're actually doing some science': primary students' perspectives of their involvement in the MyScience initiative. Research in Science Education, 49(2), 465-498. https://doi.org/10.1007/s11165-017-9633-3

Hsu, P. L., \& Roth, W. M. (2010). From a sense of stereotypically foreign to belonging in a science community: Ways of experiential descriptions about high school students' science internship. Research in Science Education, 4O(3), 291-311. https://doi.org/10.1080/09500693.2018.1479801

Jaber, L. Z., \& Hammer, D. (2016). Learning to feel like a scientist. Science Education, 10o(2), 189-220. https://doi.org/10.1002/sce.21202

Johnson, B., \& Christensen, L. (2014). Educational Research: Quantitative, Qualitative, and Mixed Approaches, Fifth Edition. Sage. 
Kim, M. (2018). Understanding children's science identity through classroom interactions. International Journal of Science Education, 4O(1), 24-45. https://doi.org/10.1080/09500693.2017.1395925

Kane, J.M. (2016). Young African American Boys Narrating Identities in Science. Journal of Research in Science Teaching, 53(1), 95-118. https://doi.org/10.1002/tea.21247

Lederman, N. G., \& Lederman, J. S. (2014). Research on teaching and learning of nature of science. In Handbook of research on science education, volume II (pp. 614-634). Routledge.

Lederman, J. S., Lederman, N. G., Bartos, S. A., Bartels, S. L., Meyer, A. A., \& Schwartz, R. S. (2014). Meaningful assessment of learners' understandings about scientific inquiry-The views about scientific inquiry (VASI) questionnaire. Journal of research in science teaching, 51(1), 65-83. https://doi.org/10.1002/tea.21125

Leslie, S. J., Cimpian, A., Meyer, M., \& Freeland, E. (2015). Expectations of brilliance underlie gender distributions across academic disciplines. Science, 347(6219), 262-265. https://doi.org/10.1126/science.1261375

Lewis, A. (1992). Group child interviews as a research tool. British Educational Research Journal, 18(4), 413-421. https://doi.org/10.1080/0141192920180407

Lombard, M., Snyder-Duch, J., \& Bracken, C. (2002) Content analysis in mass communication: assessment and reporting of intercoder reliability. Human Communications Research, 28, 587-604. https://doi.org/10.1111/j.1468-2958.2002.tboo826.x

Lyons, T. (2006). Different countries, same science classes: Students' experience of school ascience classes in their own words. International Journal of Science Education, 28(6), 591-613. https://doi.org/10.1080/09500690500339621

Newby, P. (2010). Research methods for education. London, UK: Pearson Education.

O'Connor, C., \& Joffe, H. (2020). Intercoder reliability in qualitative research: debates and practical guidelines. International Journal of Qualitative Methods, 19, 1-13. https://doi.org/10.1177/1609406919899220

Osborne, J., \& Collins, S. (2001). Pupils. views of the role and value of the science curriculum: A focus-group study. International Journal of Science Education, 23(5), 441-467. https://doi.org/10.1080/09500690010006518

Roberts, K., Dowell, A., \& Nie, J.-B. (2019). Attempting rigour and replicability in thematic analysis of qualitative research data; A case study of codebook development. BMC Medical Research Methodology, 19, 66. https://doi.org/10.1186/s12874-019-0707-y

Robson, C. (2011). Real world research. Third Edition. UK: Wiley.

Savin-Baden, M., \& Major, C. H. (2013). Qualitative research: The essential guide to theory and practice. Routledge.

Schinske, J. N., Perkins, H., Snyder, A., \& Wyer, M. (2016). Scientist spotlight homework assignments shift students' stereotypes of scientists and enhance science identity in a diverse introductory science class. CBE-Life Sciences Education, 15(3), ar47. https://doi.org/10.1187/cbe.16-01-0002

Schleicher, A. (2018). PISA 2018: Insights and Interpretations. OECD Publishing.

Thomas, J., \& Harden, A. (2008). Methods for the thematic synthesis of qualitative research in systematic reviews. BMC Medical Research Methodology, 8, 45. https://doi.org/10.1186/1471-2288-8-45

Trujillo, G., \& Tanner, K. D. (2014). Considering the role of affect in learning: Monitoring students' self-efficacy, sense of belonging, and science identity. CBE-Life Sciences Education, 13(1), 6-15. https://doi.org/10.1187/cbe.13-12-0241

Wang, H. H., Lin, H. S., Chen, Y. C., Pan, Y. T., \& Hong, Z. R. (2021). Modelling relationships among students' inquiry-related learning activities, enjoyment of learning, and their intended 
choice of a future STEM career. International Journal of Science Education, 43(1), 157-178. https://doi.org/10.1080/09500693.2020.1860266

Williams, M. M., \& George-Jackson, C. (2014). Using and doing science: Gender, self-efficacy, and science identity of undergraduate students in STEM. Journal of Women and Minorities in Science and Engineering, 20(2).

https://doi.org/10.1615/JWomenMinorScienEng.2014004477

Zhai, J., Jocz, J. A., \& Tan, A. L. (2014). 'Am I Like a Scientist?': Primary children's images of doing science in school. International Journal of Science Education, 36(4), 553-576. https://doi.org/10.1080/09500693.2013.791958

\section{Appendix 1. Student Focus Group Interview Schedule}

1. What kind of work do you think scientists do? Can you describe this?

2. Do you think there is a difference between the work a scientist would do as a job, and the kinds of science you do in the classroom?

3. Do you like science? (if yes, *, if not, "why not"?) Would you like to have a job where you would use science in the future?

4. * What is your favourite thing about science? 